\title{
Phonological assembly in reading: Lexical contribution leads to violation of graphophonological rules
}

\author{
RONALD PEEREMAN \\ Université libre de Bruxelles, Brussels, Belgium
}

\begin{abstract}
According to current models of reading, the phonological representation of a letter string could be generated by means of two different procedures. The first consists in the looking up or addressing of the phonological representation of the appropriate word in the mental lexicon. The second consists in the assignment of a phonological code to the various orthographic units that occur in the letter string and the assembly of them into a unitary phonological representation. However, the various models of phonological assembly differ in the nature of the knowledge that such assembly requires. On the one hand, dual-route theories assert that the assembly process operates by means of extralexical graphophonological rules and, therefore, without reference to lexical knowledge. On the other hand, in analogy theories and interactive models of phonological assembly, the lexical phonological representations of words orthographically close to the letter string (the orthographic neighborhood) are supposed to contribute to the translation process. The aim of the experiments reported here was to empirically distinguish between these two categories of models. In Experiment 1, subjects were asked to pronounce pseudowords containing the letter $g$. Results indicate that the phonological representation assigned to the letter $g$ depends on the pronunciation favored by the lexical neighbors. Experiment 2 shows that lexical contribution to phonological assembly also takes place in lexical decision.
\end{abstract}

According to current models of reading, the pronunciation of a letter string could be achieved in two different ways. The first procedure available to the skilled reader consists in the retrieval of the phonological representation of the letter string in the mental lexicon. In the terminology introduced by Patterson (1982), this phonological representation is said to be addressed. The second procedure consists in the assigment of a phonological representation to the various orthographic units that occur in the letter string and in the assembly of the units into a unitary phonological code. This phonological representation is said to be assembled. The most convincing argument in favor of the assembly process may be found in our ability to pronounce pseudowords, which, by definition, are not represented in the mental lexicon. Impairment of the assembly process with relative preservation of the addressing procedure should lead to larger difficulties in the naming of pseudowords as opposed to words. This dissociation has been described in the context of deep

This work was supported in part by the Fund for Joint Basic Research and by the Ministry of Scientific Policy (National Incentive Program for Fundamental Research in Artificial Intelligence). This research formed part of a doctoral dissertation presented by the author and supported by research assistant grants from the National Fund for Scientific Research (Belgium). I thank Daniel Holender, Alain Content, Paul Bertelson, Robert W. Proctor, Robert McCann, Annette M. B. de Groot, and Robert G. Crowder for their helpful comments. Requests for reprints should be sent to the author, Laboratory of Experimental Psychology, Université libre de Bruxelles, Avenue A. Buyl, 117, B1050 Brussels, Belgium. and phonological dyslexia (Coltheart, 1982; Dérouesné \& Beauvois, 1979; Funnell, 1983; Patterson, 1982).

A common view is that the time needed to assemble the phonological code of a word should be longer than the time required for addressing the phonological representation in the lexicon. In agreement with this hypothesis, it has been shown that words are pronounced faster than pseudowords (Rossmeissl \& Theios, 1982), even when the latter are homophonic with real words (Theios \& Muise, 1977). The advantage of words over pseudowords has been taken to suggest that word pronunciation is generally based on the addressed phonological representation. However, several findings (Andrews, 1982; Seidenberg, 1985; Seidenberg, Waters, Barnes, \& Tanenhaus, 1984; Taraban \& McClelland, 1987) seem to indicate that the pronunciation of not only pseudowords but also low-frequency words relies on phonological assembly. This assumption mainly follows from the interaction between frequency of usage and graphophonological regularity. The notion of graphophonological regularity corresponds to the fact that for some words, the relation between orthography and pronunciation is irregular or exceptional (e.g., deaf, touch). It has been proposed that the assembly process could yield a correct phonological representation only with regular words (Coltheart, 1978). Indeed, the use of the frequent graphophonological correspondences for assembling a phonological code of irregular words will obviously give rise to errors consisting in the pronunciation of the irregular words in a regular way. Correct pronunciation of irregular words could thus 
be achieved only by addressing the phonological representation of the word in the lexicon. The hypothesis that skilled readers make use of the assembly process in naming low-frequency words was suggested by shorter naming latencies for regular than for irregular words. This regularity effect was not observed with high-frequency words (Seidenberg et al., 1984). However, although this result gives some information about the relative speed of assembling and addressing, it leaves the nature of the procedure unspecified (see Norris \& Brown, 1985, for a discussion).

Current models of phonological assembly have generally been contrasted on the basis of whether they belong to dual-route or to analogy theories (e.g., Humphreys \& Evett, 1985). Dual-route theories assume that the two procedures available for the pronunciation of words are separate. Phonological assembly is thus supposed to be realized by means of autonomous spelling-to-sound correspondence rules stored extralexically. In other words, the main characteristic of dual-route theories lies in the assertion that the assembly process operates without reference to phonological representation of the words stored in the lexicon. Consequently, these models will be referred to here as extralexical models. The first detailed description of dual coding was originally proposed by Coltheart (1978). It was subsequently modified by Patterson and Morton (1985). The two versions differ in that only grapheme-to-phoneme rules are postulated by Coltheart, whereas Patterson and Morton also included correspondences bearing on rhyme. Additional results provided by Kay $(1985,1987)$ indicate, however, that graphophonological correspondences on the initial orthographic units of the words should also be added.

Contrary to dual-route theories, analogy theories assert that lexical knowledge is used in the assembly of a phonological representation of a letter string. According to these theories, phonological assembly is performed on the basis of units extracted from the phonological representation of words stored in the lexicon. For example, in the model proposed by Glushko (1979; see also Henderson, 1982, for discussion), lexical orthographic entries similar to the presented letter string are first activated. The corresponding phonological codes are then accessed and used in a process of synthesis that gives rise to the assembly of a unitary phonological code of the letter string. A somewhat different model of pronunciation based on analogy was presented by Marcel (1980; Kay \& Marcel, 1981). According to this model, the presented letter string is first segmented into all possible orthographic units. For each of these units, all the orthographic entries in the lexicon that contain the unit in the same position are then activated. The phonological counterparts of the lexical units are finally used to assemble a phonological representation of the letter string.

In addition to dual-route and analogy theories, a mixed model has been described by Shallice and McCarthy (1985). According to them, spelling-to-sound correspondence rules at various levels of orthographic segmenta- tion are used in parallel by the assembly process. However, contrary to the extralexical models, the phonological representation of the words stored in the lexicon also takes part in the assembly process. This lexical contribution reinforces or inhibits the units activated at the other (submorphemic) levels of segmentation. In other words, the mixed model includes feedback connections between the word level and extralexical phonology. Because both analogy and mixed models argue that lexical knowledge participates in the assembly process, I will refer to them as lexical models (as opposed to extralexical models).

Several studies have been conducted to test extralexical and lexical models. However, according to Patterson and Morton (1985; see also Coltheart, 1985), the data initially considered as supporting analogy theories are also compatible with a modified version of dual-route theories. Consider, for instance, the word-consistency effect described by Glushko (1979), who found longer naming latencies for regular words with an irregular neighbor (regular inconsistent words; e.g., gave with have irregular) than for regular words without an irregular neighbor (regular consistent words; e.g., gaze). Such a result could be explained within the framework of dual-route theories by supposing that the extra time required to name the inconsistent words is caused by a conflict between the alternative graphophonological rules (-ave rhyming with have or with gave). Moreover, the word-consistency effect, which has provided the main empirical evidence in favor of the analogy models, has appeared to result from a bias introduced by the irregular neighbor preceding the regular word in the list of stimuli (Seidenberg et al., 1984; Stanhope \& Parkin, 1987). Nevertheless, results described by Kay and Marcel (1981) have forced a rules updating process to be incorporated into dual-route theories (Patterson \& Morton, 1985). When a word (e.g., touch or couch) is pronounced, the strengths of the graphophonological rules compatible with the orthographic and phonological representations of the word are updated. If an ambiguous pseudoword (which can be pronounced in more than one way; e.g., nouch) is subsequently presented, the primed rules will have a higher probability of being used during phonological assembly. According to Patterson and Morton, this assumption does not challenge the nonlexical hypothesis, however. Indeed, although pronunciation of previously encountered words updates the strengths of some graphophonological rules, the assembly process remains nonlexical in that "no reference would be made, at the time of assembling the phonological code, to correspondences between orthography and phonology in specific known words" (p. 336).

As Patterson and Morton (1985) acknowledge, results described by Rosson (1983) nevertheless provide difficulties for dual-route theories. In a priming situation, Rosson showed that the phonological representation assigned to a pseudoword orthographically similar to regular and irregular words (e.g., louch has couch and touch as regular and irregular neighbors, respectively) was dependent on the prime. Irregular pronunciations of the pseudowords 
were more frequent when the prime word was semantically associated with the irregular neighbor (e.g., feel associated with touch) than when the prime word was associated with the regular neighbor (e.g., sofa associated with couch). In accounting for this result, Rosson suggested that lexical knowledge is used in phonological assembly. However, these results are inconclusive. Indeed, as Henderson (1985) has mentioned, a problem encountered in Rosson's (1983) study is that priming could induce response strategies by the subject's detecting the existing relation between prime and target. Experiment 1 was therefore planned to test whether or not lexical contribution occurs during phonological assembly without recourse to a priming technique.

\section{EXPERIMENT 1}

Experiment 1 takes advantage of previous data collected in an unpublished experiment on phonological priming. It was observed that the subjects sometimes erroneously pronounced pseudowords that contained the French letters $c$ and $g$ or the bigrams $c c$ and $s c$ (in initial position) whose pronunciation depends on the following vowel. Similar observations have been reported by Baron (1977) and more recently by Masterson (1985) and by Brown and Besner (1987). In the present experiment, subjects were asked to pronounce pseudowords that contained the letter $g$. In French, the letter $g$ is always pronounced $/ 3 /$ before $e, i$, or $y$ and $/ \mathrm{g} /$ before $a, u$, or $o$. The pseudowords were constructed in such a way that the pronunciation expected on the basis of extralexical models was different from the pronunciation expected on the basis of lexical models. Extralexical models predict that the percentage of mispronunciations will not vary as a function of the overlap between the pseudoword and a real word. Conversely, lexical models predict that the pronunciation given to the letter $g$ will depend on the pronunciation favored by the orthographic neighbors.

Three types of pseudowords orthographically close to real words were used in the experiment. The peculiarity of the pseudowords of the first category was that, whatever the pronunciation adopted for the letter $g$, they were never homophonic with the orthographically close word (e.g., the pseudoword girnir is derived from the word garnir). These pseudowords will be referred to as nonhomophonic pseudowords. The pseudowords of the second type were homophonic with one real word only when the $g$ was erroneously pronounced. An example of a pseudoword is gavelot, which is homophonic with the French word javelot if the letter $g$ is mispronounced $(/ 3 /$ instead of $/ g /$ ). These pseudowords will be referred to as homophonic-if-erroneous pseudowords. The pseudowords of the third type were homophonic with their neighbors when the letter $g$ was correctly pronounced (e.g., geudi, derived from the word jeudi). They will be referred to as homophonic-if-correct pseudowords. Control pseudowords were derived from each pseudoword of the three categories. If lexical information is used in the assembly process, the number of mispronunciations of the $g$ will be larger for nonhomophonic and homophonic-if-erroneous pseudowords than for their controls. In addition, the errors should be more frequent for homophonic-if-erroneous pseudowords than for nonhomophonic pseudowords and less numerous for the homophonic-if-correct pseudowords than for their controls.

\section{Method}

Subjects. Eleven university students took part in the experiment. All were native French speakers. They were paid for participating.

Stimuli. Three categories of pseudowords containing the letter $g$ were created. Each pseudoword of the first category was identical to one word, except for the vowel following the $g$ (e.g., girnir for the word garnir). Whatever the pronunciation adopted for the letter $g$, the pseudowords of the first category were never homophonic with their lexical neighbors. The 23 nonhomophonic pseudowords of the first category were matched with 23 control pseudowords. The control pseudowords were derived from the nonhomophonic pseudowords by substituting two letters, leaving the vowel following the $g$ unchanged (e.g., girler for the nonhomophone girnir). Each pseudoword of the second category was identical to one word, except for one letter. Contrary to the pseudowords of the first category, each pseudoword of the second category was homophonic with its lexical neighbor if the letter $g$ was erroneously pronounced (e.g., gavelot for the word javelot). The 28 homophonic-if-erroneous pseudowords of the second category were matched with 28 control pseudowords. These control pseudowords were generated by substituting two letters (on the average) of the homophonic-if-erroneous pseudowords (e.g., gamevot for gavelot). The pseudowords of the third category were homophonic with their lexical neighbor when the letter $g$ was correctly pronounced (e.g., geudi for jeudi). The 22 homophonic-if-correct pseudowords were matched with 22 control pseudowords (e.g., geuma for geudi). The stimuli are given in Appendix A. Thirty additional pseudowords and 150 words were included as fillers in the list of stimuli, in order to decrease the probability of occurrence of the letter $g$. A second reason for adding words was to preclude any specific coding strategy for pseudowords, since data suggest that coding flexibility occurs in the naming task. For instance, word naming is faster when the list does not include pseudowords than when it does (Andrews, 1982; Frederiksen \& Kroll, 1976). It has also been shown that the frequency effect in Dutch (Hudson \& Bergman, 1985) and the associative priming effect in Italian (Tabossi, 1989) vanish when pseudowords are added to the word list.

Procedure. The letter strings appeared singly in capital letters on a video screen. Presentation and timing were controlled by an Apple Ile. The experimental session began with 15 practice trials. Because the main interest of Experiment 1 lay in pronunciation errors, the instructions given to the subject emphasized the demand to pronounce the letter strings as quickly as possible. Although not of primary interest, response latencies were also recorded. The response activated a voice key connected to the microprocessor. The pronunciations were recorded on a Sony recorder and transcribed by the experimenter. Each trial began with a warning signal (a "+" sign) presented for $300 \mathrm{msec}$. It was immediately followed by the letter string. The target remained on the screen until the response was made and for a maximum of $2 \mathrm{sec}$ if it was not. The intertrial interval was $1 \mathrm{sec}$.

\section{Results}

All errors that did not correspond to-and only tomispronunciations of the letter $g$ were excluded from the analysis. Thus, discarded responses also included erroneous pronunciations consisting of an error on the letter $g$ 
plus an error on another part of the pseudoword. This led to the rejection of $6 \%$ of the trials. Note that the number of lexicalizations (pronunciation of a word instead of the pseudoword) that did not correspond to mispronunciations of the $g$ is relatively small $(0.7 \%$ of the trials of the three control conditions and the nonhomophone pseudoword condition; $1.6 \%$ if the nonhomophonic pseudowords are considered alone). Percentages of errors corresponding only to mispronunciations of the letter $g$ were calculated on the remaining $94 \%$ of the trials. The results are reported in Figure 1.

Percentages of errors were examined in an analysis of variance (ANOVA), in which the factors were neighborhood (test pseudoword with a neighbor; control pseudoword) and category nested within neighborhood (nonhomophonic pseudowords, homophonic-if-erroneous pseudowords, homophonic-if-correct pseudowords, and matched controls). Because of unequal sample sizes, item analysis was carried out with the method of unweighted means (in this method, the analysis is based on transformed means that correspond to the means multiplied by the average number of items per condition; see Keppel, 1982, for further discussion). As Figure 1 shows, the percentages of errors varied between the three categories of pseudowords with or without neighbors $[F(4,40)=21.36$, $p<.01$, per subject; $F(4,140)=13.53, p<.01$, per item]. The factor of neighborhood was nonsignificant, probably because of the differential effect of neighborhood in the three categories of pseudowords.

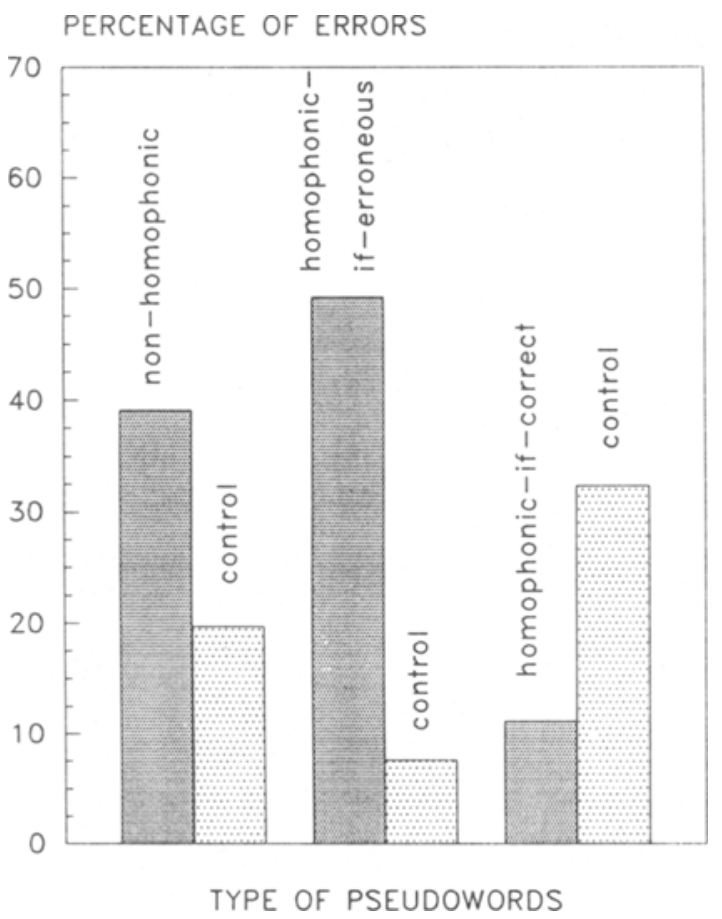

Figure 1. Percent errors in Experiment 1, as a function of type of pseudoword.
Table 1

Mean Naming Latencies (in Milliseconds) in Experiment 1

\begin{tabular}{lccc}
\hline \multicolumn{4}{c}{ Pseudoword Categories } \\
\hline & Nonhomophonic & $\begin{array}{c}\text { Homophonic-If- } \\
\text { Erroneous }\end{array}$ & $\begin{array}{c}\text { Homophonic-If- } \\
\text { Correct }\end{array}$ \\
\hline Test & 506 & 493 & 475 \\
Control & 504 & 522 & 514 \\
\hline
\end{tabular}

The specific predictions made in the introduction were tested through planned comparisons. As can be seen in Figure 1, errors were more frequent with nonhomophonic pseudowords than with their controls $[F(1,10)=31.38$, $p<.01$, per subject; $F(1,44)=8.13, p<.01$, per item] and more frequent with homophonic-if-erroneous pseudowords than with their controls $[F(1,10)=213.72, p<$ .01 , per subject; $F(1,54)=53.13, p<.01$, per item]. In contrast, errors were less numerous with homophonicif-correct pseudowords than with their controls $[F(1,10)$ $=12.54, p<.01$, per subject; $F(1,42)=10.65, p<$ .01 , per item].

Because errors were more frequent for the controls of nonhomophonic pseudowords than for the controls of homophonic-if-erroneous pseudowords, direct comparison between nonhomophonic and homophonic-if-erroneous pseudowords is not appropriate. Comparison was therefore based on the increase in errors relative to performance with controls. As Figure 1 shows, the difference in percentages of errors was larger between homophonic-iferroneous pseudowords and their controls than between nonhomophonic pseudowords and their controls $[t(10)=$ $5.53, p<.01$, per subject; $t(49)=2.76, p<.01$, per item].

An analysis was also performed on response times (RTs). However, because of differences between the three item categories in terms of number of syllables, number of letters, and initial phonemes, only the three planned comparisons were carried out. Errors and RTs exceeding $900 \mathrm{msec}$ or smaller than $200 \mathrm{msec}$ were excluded from the analysis. In addition, because the number of correct RTs was relatively small and because the items were not matched across the three categories, it was necessary to consider only RTs for instances in which the test pseudoword and its matched control were correctly pronounced. Mean response latencies in the three categories are given in Table 1. These results are based on $37 \%, 37 \%$, and $48 \%$ of the items in the nonhomophonic, homophonic-iferroneous, and homophonic-if-correct pseudoword conditions, respectively.

As can be seen in Table 1, response latencies were shorter for the homophonic-if-correct pseudowords than for their controls $[F(1,10)=5.79, p<.05$, per subject; $F(1,42)=11.10, p<.01$, per item]. The difference between homophonic-if-erroneous pseudowords and controls was significant in the subject analysis $[F(1,10)=5.19$, $p<.05]$ but far from significant in the item analysis $(p>$ .10). The difference between nonhomophones and controls was not significant, neither by subject nor by item. 


\section{Discussion}

The results of Experiment 1 indicate that the phonological knowledge from the lexicon is used in assigning a phonological representation to a letter string. In agreement with the predictions of the lexical models, the phonological representation attributed to the letter $g$ depends on the phonological representation favored by the orthographic neighbors. On the one hand, when the pronunciation favored by the orthographic neighbor is compatible with the correct pronunciation of the letter $g$, the errors are less numerous and naming latencies are shorter than they are for the controls. This result is in agreement with previous data (McCann \& Besner, 1987; Pring \& Snowling, 1986) that have revealed an advantage for homophonic pseudowords over nonhomophonic pseudowords in naming latencies. On the other hand, when the pronunciation favored by the orthographic neighbor is compatible with the incorrect pronunciation of the $g$, errors are more frequent than they are for the controls. The data collected with the nonhomophonic pseudowords and the homophonicif-erroneous pseudowords show that the neighbor involvement in the assembly process leads to an increase of erroneous responses consisting in violation of the spellingto-sound rules of the letter $g$. These results are incompatible with extralexical models.

One aspect of the data deserves further consideration. The results indicate that naming latencies did not increase when the pronunciation of the $g$ favored by the orthographic neighbor conflicted with the pronunciation expected from rules. At first sight, this observation seems incompatible with data on the consistency effect for pseudowords. Both Glushko (1979) and Stanhope and Parkin (1987) showed that letter strings that can be pronounced either regularly or irregularly (e.g., tave with the -ave pronounced to thyme with have or with gave) give rise to longer naming latencies than do letter strings whose pronunciation is unique. ${ }^{1}$ This result suggests that interference occurs between the alternative phonological codes of the orthographic unit. More interesting for the present context is that Stanhope and Parkin showed that interference was reduced by priming the pseudoword with the regular word (e.g., gave-tave) but not augmented by priming with the irregular word (e.g., have-tave). However, priming with the irregular word increased the number of irregularizations (pronouncing with the irregular pronunciation). Since, in Experiment 1, both controls and test pseudowords included the letter $g$, longer latencies to tests than to controls were not observed. Just as priming with the regular word reduced interference in the Stanhope and Parkin study, naming latencies were shorter when the lexical neighbor favored the correct pronunciation of the $g$. When the lexical neighbor favored the incorrect pronunciation, naming latencies did not increase relative to latencies to controls, but the incorrect pronunciation was more often produced.

As has been revealed by the comparison between homophonic-if-erroneous pseudowords and nonhomophonic pseudowords, the increase in the number of errors (rela- tive to performance on controls) was larger when the erroneous pronunciation corresponded to a word than when it did not. These data are parallel to those described by Saffran (1985) in a surface dyslexic patient. It appeared that the vowels included in words and pseudowords were more frequently mispronounced when the erroneous phonological representation of the letter string was homophonic with a word (e.g., grine with a short vowel pronunciation) than when it did not correspond to a word (e.g., crine). However, an alternative explanation for the larger increase in errors with the homophonic-if-erroneous pseudowords than with the nonhomophonic pseudowords is that the frequencies of the orthographic neighbors may be, on the average, higher for the former than for the latter. Consequently, the likelihood that orthographic neighbors would be involved in the assembly process could be larger for the homophonic-if-erroneous pseudowords than for the nonhomophonic pseudowords. To evaluate this possibility, 14 subjects rated each word for frequency on a 6-point scale (from $1=$ unknown to 6 = very frequent). Mean subjective frequencies $\times 100$ were 400 for the nonhomophonic pseudowords and 412 for the homophonicif-erroneous pseudowords. The difference was not significant. Thus, the larger number of errors observed with homophonic-if-erroneous pseudowords than with nonhomophonic pseudowords cannot be attributed to differences in the frequency of the orthographic neighbors.

An unexpected observation is that the number of errors is larger for the controls of homophonic-if-correct pseudowords than for the controls of nonhomophonic and homophonic-if-erroneous pseudowords (see Figure 1). The reason for this is that the $g$ that should be pronounced 13 / (the soft $g$ ) is more frequently mispronounced than the $g$ that should be pronounced $/ g /$ (the hard $g$ ). Overall, the control pseudowords including the soft $g$ gave rise to $26 \%$ of errors, whereas $7 \%$ of the errors were observed with the pseudowords including the hard $g$. How can the hard $g$ bias be explained? Detailed analysis shows that the large number of errors with the controls of the homophonic-if-correct pseudowords is partly due to the pseudowords' including the unusual French trigram geu. Fortyeight percent of the errors in that condition were caused by the 6 pseudowords including the geu trigram. However, since the geu trigram did not occur in the two other control conditions, the reason of more frequent errors with the soft $g(22.7 \%)$ than with the hard $g(6.8 \%)$ remains unclear. Note also that the two spelling-to-sound rules are almost equally frequent in French. In an analysis based on a corpus of 3,724 words, Véronis (1986) found nearly equivalent frequencies of the two rules. Similar results were obtained with a corpus of 35,746 words (Content, Mousty, \& Radeau, in press). Among the words including the letter $g$, the pronunciations $/ 3 /$ and $/ g /$ occur in $45 \%$ and $55 \%$ of the cases, respectively. If, however, word frequency is taken into account, the difference between the two rules disappears $(49 \%$ and $51 \%$ for the soft and hard pronunciations, respectively). In addition, in Experiment 1 , the soft $g$ occurred more often than the hard 
$g$ (56\% and $44 \%$, respectively). ${ }^{2}$ In order to examine whether the bias toward the $/ g /$ pronunciation evolved during the experiment, an additional analysis was conducted by comparing the percentages of errors in the first and the second halves of the experiment. The results show that, in the three control conditions, the percentages of errors $(/ \mathrm{g} /$ pronunciation instead of $/ 3 /)$ were approximately the same in the first and the second halves of the experiment $(25.4 \%$ and $26.7 \%$, respectively).

Although the reason for the bias favoring the hard $g$ over the soft $g$ is not clear, it should be noted that this observation does not constitute a problem in the interpretation of the data. Indeed, the correct pronunciation of the $g$ included in each test pseudoword was always identical to that of the $g$ included in its matched control. In addition, errors on the soft $g$ were less frequent with the homophonic-if-correct pseudowords than with their controls. This suggests that the lexical contribution during phonological assembly overrode the bias in favor of the hard $g$ pronunciation. In the two other conditions (nonhomophonic and homophonic-if-erroneous pseudowords) the bias toward the hard $g$ observed with the controls also vanished with the test pseudowords $(44.0 \%$ of errors on the $g$ that should be pronounced $/ \mathrm{g} /$ and $45.7 \%$ of errors on the $g$ that should be pronounced $/ 3 /$ ). As for the homophonic-if-correct pseudowords, the later result indicates that the neighbors are used during phonological assembly and that the lexical contribution overrides the bias in favor of the hard $g$ pronunciation.

The results of Experiment 1 suggest that lexical knowledge contributes to phonological assembly. In the framework of extralexical models, the lexical contribution should be located at a processing stage later than phonological assembly. The unattractive aspect of this suggestion is that it requires duplication of parts of the assembly process (e.g., the synthesis of a unitary phonological code) for lexical knowledge to be integrated into the assembled phonological code. However, it remains possible that the conflict between the lexical phonological code of the neighbor and the assembled phonological code leads, in order for pronunciation to occur, to the derivation of a new phonological or articulatory code incorporating the lexical information. Therefore, Experiment 2 was conducted to examine whether errors on the letter $g$ also occur when the task does not require an overt pronunciation of the letter string and can be performed without the necessary use of a phonological code.

\section{EXPERIMENT 2}

In Experiment 2, performance in response to presentations of homophonic-if-erroneous pseudowords were examined in a lexical decision task. If these pseudowords are incorrectly assembled before the response, decision latencies should be longer and false positive responses more frequent than they would be for matched control pseudowords. If the lexical neighbor is involved in the process of assembly, an incorrect phonological represen- tation will be assigned to the letter $g$. Consequently, the incorrectly assembled phonological code of the homophonic-if-erroneous pseudowords should correspond to a phonological entry. Therefore, we can predict more errors for the test pseudowords than for the controls. In addition, as has been shown in the case of pseudowords really homophonic with a word (e.g., brane; Besner \& Davelaar, 1983; Rubenstein, Lewis, \& Rubenstein, 1971), the decision latencies for correct negative responses should be longer with homophonic-if-erroneous than with control pseudowords. The slowing down of the responses should arise from conflicting decisions based on the phonological and orthographic information.

\section{Method}

Subjects. Sixteen subjects took part in the experiment. Owing to too numerous errors on homophonic-if-erroneous pseudowords $(57 \%), 1$ subject was removed and replaced with another subject. None of them had participated in Experiment 1. All were native French speakers and were pard for participating.

Stimuli. The stimuli consisted of 80 words (frequent or rare) and 80 pseudowords. There were 21 homophonic-if-erroneous pseudowords (e.g., gitare and pigon, derived from the words guitare and pigeon). As in Experiment 1, these pseudowords were homophonic with the word from which they were derived only when the $g$ was mispronounced. Twenty-one control pseudowords were matched with the homophonic-if-erroneous pseudowords. They were constructed in the following manner. Each word (e.g., pigeon) orthographically close with the used homophonic-if-erroneous pseudowords (e.g., pigon) was matched with another word of identical consonant-vowel structure (e.g., vapeur). The control pseudowords (e.g., vapur) were then derived in the same way as the homophonicif-erroneous pseudowords were derived from the orthographically close word. For example, the control pseudoword vapur was derived from the French word vapeur by suppressing the fourth letter, just as the test pseudoword pigon was derived from the word pigeon. The two categories of pseudowords were matched as closely as possible for positional bigram frequencies (Content \& Radeau, 1988). Mean log bigram frequencies weighted by word frequency $\times 100$ were 297 and 302 for the homophonic-if-erroneous pseudowords and the controls, respectively. In addition, the two categories of pseudowords were also matched in terms of frequency of the words from which they were derived (their lexical neighbors). This matching is important, given that O'Connor and Forster (1981) showed that false positive responses to pseudowords were more frequent when the orthographically close word was of high frequency than when it was of low frequency. Mean log frequencies $\times 100$ of the orthographically close words (based on Imbs, 1971, in which frequencies are indicated as if they were calculated on a sample of 100 million) were 286 and 322 for the homophonic-if-erroneous pseudowords and the controls, respectively. The stimuli are given in Appendix B. In addition, 38 other pseudowords were included in the list as fillers. These fillers were added in order to decrease the probability of occurrence of the letter $g$ in the experimental session. The 160 stimul were divided into two blocks of identical length.

Procedure. The stimuli, printed in lowercase, were presented singly on a video screen. The subjects were told that they would be presented with letter strings and that they had to decide as quickly and accurately as possible if it was a word or a nonword. Responses were given with the preferred hand by pushing the responding lever for words and by pulling it toward the body for pseudowords. Order of presentation of the two blocks was counterbalanced across subjects. The experiment began with 34 practice trials. As in Experiment 1 , each trial began with a warning signal presented for 
$300 \mathrm{msec}$. It was followed by the letter string remaining on the screen until the response was made ( $2 \mathrm{sec}$ maximum). The intertrial interval was $1 \mathrm{sec}$.

\section{Results}

Decision latencies exceeding $1,200 \mathrm{msec}$ or smaller than $200 \mathrm{msec}$ ( $7.7 \%$ of the pseudowords and $2.2 \%$ of the words) were excluded from the analysis. Mean response time for homophonic-if-erroneous pseudowords was $791 \mathrm{msec}$, whereas mean response time for controls was $739 \mathrm{msec}$. The corresponding percentages of errors were $17.3 \%$ and $7.7 \%$. Planned comparisons were performed on the data for the pseudowords. Lexical decision latencies were longer for homophonic-if-erroneous pseudowords than for controls $[t(15)=4.75, p<.01$, per subject; $t(40)=3.02, p<.01$, per item]. In addition, errors were more frequent for homophonic-if-erroneous pseudowords than for their controls $[t(15)=3.07$, $p<.01$, per subject; $t(40)=2.61, p<.05$, per item].

\section{Discussion}

The results of Experiment 2 indicate that incorrect phonological representation is also assigned to the letter $g$ when the task does not necessarily require the assembly of a phonological representation. The longer latencies and the larger number of errors for homophonic-iferroneous pseudowords than for controls suggest that lexical knowledge is used during the phonological assembly of the letter strings. Since the neighbors of the homophonic-if-erroneous pseudowords favored the assignment of an incorrect phonological representation to the letter $g$, the assembled phonological code will correspond to a real word. It follows that erroneous positive responses will be given to the pseudowords. For correct responses, the decision based on the phonological information conflicts with the decision based on the orthographic information. This is the reason why there is an increase in response latencies for the homophonic-if-erroneous pseudowords relative to the controls.

\section{GENERAL DISCUSSION}

The results of Experiment 1 show that the pronunciation of pseudowords is influenced by specific word knowledge. The French letter $g$ occurring in pseudowords was more often mispronounced when the letter string was orthographically similar to a real word favoring an erroneous pronunciation of the $g$. Conversely, the number of mispronunciations was reduced when the pseudoword was orthographically similar to a word favoring the correct pronunciation of the $g$. Hence, despite the fact that, in French, the pronunciation of the letter $g$ always depends on the following letter, the graphophonological rules were violated because of the lexical contribution to phonological assembly. Therefore, extralexical models implying that lexical knowledge is not involved in phonological assembly are unable to deal with the present data. As I shall propose below, Experiments 1 and 2 suggest that models postulating separate sources of stored knowledge (words and submorphemic graphophonological associations) should allow for interactions to occur between them when the phonological code is assembled.

The hypothesis of interaction between the two procedures for pronouncing has been one of the main topics discussed during the last few years. It has been mentioned that the assumption of strict independence of the two procedures failed to account for longer naming latencies with irregular as opposed to regular words (see Henderson, 1982, for discussion). However, although the strict independence hypothesis was abandoned, the interactions were generally supposed to take place after the assembled phonological code was already derived (see Humphreys \& Evett, 1985, for a summary of the different propositions). In other words, it was suggested that the interactions occur between the outputs of the two procedures. Thus, the increase in response latencies for irregular words is generally supposed to result from a mismatch between the correct addressed phonological code and the incorrect assembled phonological code (see, e.g., Norris \& Brown, 1985, and Patterson \& Morton, 1985; but see Brown, 1987, for a different explanation). Unlike with words, such a mismatch is not expected with pseudowords, since they do not have lexical entries. In addition, whereas regular and irregular words differ in terms of frequency of their graphophonological associations (e.g., -ave is more often pronounced as rhyming with gave than with have), both test and control stimuli, in Experiment 1, included the letter $g$, whose pronunciations of $/ 3 /$ or $/ g /$ are equally frequent in French and are clearly defined by contextual rules. In other words, a well-specified algorithm for assembling without reference to lexical knowledge but including contextual rules should lead to $100 \%$ correct responses. Thus, the only difference between test and control pseudowords rests in the fact that the former, but not the latter, are similar to a word favoring either a correct or an incorrect pronunciation. In Experiment 1, it was assumed that assembling without reference to specific knowledge should preclude any effect of the lexical neighbor on the number of mispronunciations of the $g$. Although the results for the controls show that the contextual rules are sometimes misapplied, the data on the test pseudowords indicate that reference to specific words prevails over contextual rules. These findings clearly disagree with the nonlexical hypothesis. If specific word knowledge did not contribute to phonological assembly, mispronunciation of the $g$ should have the same probability of occurring with test and control pseudowords. In the lexical decision task used in Experiment 2, it was shown that reference to lexical knowledge during phonological assembly leads to a phonological code homophonic with a real word. As a consequence, errors were more frequent and correct responses slower with the homophonic-if-erroneous pseudowords than with the controls.

The present data seem to rule out the hypothesis of phonological assembly without reference to specific word knowledge. They do not necessarily imply that lexical 
knowledge alone is used during phonological assembly. In a mixed model such as the one proposed by Shallice and McCarthy (1985), the influence of the lexical neighbor on the choice of the phonological representation of the $g$ is supposed to result from inhibititory or excitatory connections between the morphemic and submorphemic levels of segmentation. It has sometimes been noted that the distinction between analogy and mixed models is blurred once it is admitted that both stored submorphemic graphophonological associations and specific word knowledge are used during phonological assembly (e.g., Norris \& Brown, 1985). However, whether submorphemic graphophonological mappings are supposed to be stored explicitly (Seidenberg et al., 1984; Shallice \& McCarthy, 1985) or retrieved by analogy as in Glushko's (1979) model is a different issue than that of the existence of graphophonological rules reflecting generalities about word pronunciation in the language. As several authors (e.g., Carr \& Pollatsek, 1985; Henderson, 1982) have mentioned, analogy models without stored submorphemic graphophonological mappings have difficulties in accounting for the pronunciation of pseudowords without lexical neighbors. Kay and Marcel's (1981) model avoids this problem by incorporating submorphemic graphophonological associations in the lexicon. Therefore, the main difference between such a model and a mixed model is that the former assumes that graphophonological mappings are stored with each specific word, whereas in the latter, stored graphophonological rules correspond to generalizations about the pronunciation of letters or letter strings in the language.

The question of generality of graphophonological associations was not addressed in the present experiments. However, the results with control pseudowords in Experiment 1 seem to present a problem if we reject the view of the generality of the graphophonological associations. It is logical to suppose that, in this case, the probability of occurrence of the soft or hard pronunciation of the letter $g$ will essentially depend on the cohort of specific words activated. By contrast, in a mixed model, the pronunciation attributed to the letter $g$ will depend both on specific words and on general, abstract knowledge about the pronunciation of letters or letter strings in the language. Therefore, it is not clear how the general tendency in favor of the hard pronunciation observed with the control pseudowords could be explained if the generality view were rejected. If the generality hypothesis is adopted, this tendency could be attributed to a (natural or artifactual) bias in favor of the $g \rightarrow / g /$ rule. If graphophonological mappings are supposed to be stored with each specific word, we are forced to assume that the words activated by the pseudoword are more often compatible with a hard than with a soft pronunciation of the $g$. This hypothesis seems unlikely, since the two rules are equally frequent in French and the control pseudowords were not more similar to words favoring the hard as opposed to the soft pronunciation of the $g$.
The question examined in Experiments 1 and 2 concerned the participation of lexical knowledge in phonological assembly. The results show that the pronunciation of pseudowords depends on the pronunciation of lexical neighbors. As noted, the data are compatible both with analogy theories and with mixed models of phonological assembly. At first sight, they also agree with the model recently proposed by Seidenberg and McClelland (1989; see also Besner, 1990, and Besner, Twilley, McCann, \& Seergobin, 1990, for a critical discussion). This model represents a special case of analogy theory in which not only the same knowledge, but also the same procedure is used in the pronunciation of words (regular as well as irregular) and pseudowords. Thus, in contrast with all the previous models, Seidenberg and McClelland's (1989) model has a single procedure for the pronunciation of letter strings. One central feature of the model is the use of distributed representations. Thus, a specific word corresponds to a specific pattern of activation over several units, and similar words are encoded by similar patterns of activation. It follows that phonological output of a pseudoword depends on the phonological codes associated with all orthographically similar words. As in Experiment 1, erroneous phonological encoding of the letter $g$ occurring in nonhomophonic and homophonic-iferroneous pseudowords is therefore likely to occur. It remains to be seen, however, whether percentages of correct and erroneous responses produced by the model would be similar to those observed in Experiments 1 and 2 .

\section{REFERENCES}

ANDREws, S (1982) Phonological recoding: Is the regularity effect consistent? Memory \& Cognition, 10, 565-575

BARON, J. (1977). What we might know about orthographic rules. In S Dornic (Ed.), Attention and performance VI (pp. 557-572). London: Academic Press.

BESNER, D (1990). Does the reading system need a lexicon? In D. A. Balota, G. B. Flores d'Arcais, \& K. Rayner (Eds.), Comprehension processes in reading (pp. 73-99) Hillsdale, NJ: Erlbaum

Besner, D., \& DavelaAr, E. (1983) Suedohomofoan effects in visual word recognition. Evidence for phonological processing. Canadian Journal of Psychology, 37, 300-305.

Besner, D., Twilley, L., McCann, R. S., \& Seergobin, K. (1990). On the association between connectionism and data: Are a few words necessary? Psychological Review, 97, 432-446.

Brown, G. D A. (1987). Resolving inconsistency: A computational model of word naming. Journal of Memory \& Language, 26, 1-23.

Brown, P., Besner, D. (1987). The assembly of phonology in oral reading: A new model. In $\mathrm{M}$. Coltheart (Ed.), Attention \& performance XII: The psychology of reading (pp. 471-489). Hillsdale, NJ: Erlbaum.

Carr, T. H., Pollatsek, A. (1985). Recognizing printed words: A look at current models. In D. Besner, T. G. Waller, \& G. E. MacKinnon (Eds.), Reading research: Advances in theory and practice (Vol. 5, pp. 1-82). New York: Academic Press.

Coltheart, M. (1978). Lexical access in simple reading tasks. In G. Underwood (Ed.), Strategies of information processing (pp. 151216). London: Academic Press.

Coltheart, M. (1982). The psycholinguistic analysis of acquired dyslexias: Some illustrations. Philosophical Transactions of the Royal Society of London, B298, 151-164. 
Coltheart, M. (1985). In defense of dual-route models of reading. Behavioral \& Brain Sciences, 8, 709-710.

Content, A., \& Radeau, M. (1988). Données statistiques sur la structure orthographique du français. Cahiers de Psychologie Cognitive, 8, 399-404.

Content, A., Mousty, P., \&Adeav, M. (in press). Bnilex: Une base de données lexicales informatisée pour le français écrit et parlé. $\mathrm{Ca}$ hiers de Psychologie Cognitive.

Dérouesné, J., \& Beauvors, M. F. (1979). Phonological processing in reading: Data from alexia. Journal of Neurology, Neurosurgery \& Psychiatry, 42, 1125-1132.

Frederiksen, J. R., Kroll, J. F. (1976). Spelling and sound: Approaches to the internal lexicon. Journal of Experimental Psychology: Human Perception \& Peformance, 2, 361-379.

FunNell, E. (1983). Phonological processes in reading: New evidence from acquired dyslexia. British Journal of Psychology, 74, 159-180.

GLushko, R. J. (1979). The organization and activation of orthographic knowledge in reading aloud. Joumal of Experimental Psychology: Human Perception \& Performance, 5, 674-691.

HeNDERSON, L. (1982). Orthography and word recognition in reading. London: Academic Press.

Henderson, L. (1985). Issues in the modelling of pronunciation assembly in normal reading. In K. E. Patterson, J. C. Marshall, \& M. Coltheart (Eds.), Surface dyslexia: Neuropsychological and cognitive studies of phonological reading (pp. 459-508). Hillsdale, $\mathrm{NJ}$ : Erlbaum.

Hudson, P. T. W., \& Bergman, M. W. (1985). Lexical knowledge in word recognition: Word length and word frequency in naming and lexical decision tasks. Journal of Memory \& Language, 24, 46-58.

HumphreYs, G. W., EveTt, L. J. (1985). Are there independent lexical and nonlexical routes in word processing? An evaluation of the dual-route theory of reading. Behavioral \& Brain Sciences, 8, 689-740.

ImBs, P. (1971). Etudes statistiques sur le vocabulaire français. Dictionnaire de fréquences. Vocabulaire littéraire des XIXe et XXE siècles. Centre de recherche pour un Trésor de la langue française (CNRS), Nancy. Paris: Librairie Marcel Didier.

KAY, J. (1985). Mechanisms of oral reading: A critical appraisal of cognitive models. In A. W. Ellis (Ed.), Progress in the psychology of language (Vol. 2, pp. 73-105). Hillsdale, NJ: Erlbaum.

KAY, J. (1987). Phonological codes in reading: Assignment of sub-word phonology. In D. A. Allport, D. Mackay, W. Printz, \& E. Scheerer (Eds.), Language perception and production (pp. 181-196). London: Academic Press.

KAY, J., MARCEL, T. (1981). One process, not two, in reading aloud: Lexical analogies do the work of non-lexical rules. Quarterly Journal of Experimental Psychology, 33A, 397-413.

KEPPEL, G. (1982). Design and analysis. A researcher's handbook (2nd ed.). Englewood Cliffs, NJ: Prentice-Hall.

MARCEL, T. (1980). Surface dyslexia and beginning reading: A revised hypothesis of the pronunciation of print and its impairments. In M. Coltheart, K. Patterson, \& J. C. Marshall (Eds.), Deep dyslexia (pp. 227258). London: Routledge \& Kegan Paul.

Masterson, J. (1985). On how we read non-words: Data from different populations. In K. E. Patterson, J. C. Marshall, \& M. Coltheart (Eds.), Surface dyslexia: Neuropsychological and cognitive studies of phonological reading (pp. 289-299). Hillsdale, NJ: Erlbaum.

MCCANN, R. S., BESNER, D. (1987). Reading pseudohomophones: Implications for models of pronunciation assembly and the locus of word-frequency effects in naming. Joumal of Experimental Psychology: Human Perception \& Performance, 13, 14-24.

NorRIs, D., \& Brown, G. (1985). Race models and analogy theories: A dead heat? Reply to Seidenberg. Cognition, 20, 155-168.

O'CONNOR, R. E., \& Forster, K. I. (1981). Criterion bias and search sequence bias in word recognition. Memory \& Cognition, 9, 78-92.

Patterson, K. E. (1982). The relation between reading and phonological coding: Further neuropsychological observations. In A. W. Ellis (Ed.), Normality and pathology in cognitive functions (pp. 77111). London: Academic Press.
Patterson, K. E., \& Morton, J. (1985). From orthography to phonology: An attempt at an old interpretation. In K. E. Patterson, J. C. Marshall, \& M. Coltheart (Eds.), Surface dyslexia: Neuropsychological and cognitive studies of phonological reading (pp. 335-359). Hillsdale, NJ: Erlbaum.

PeEReman, R. (1989). Représentations phonologiques dans la prononciation et lidentification des mots écrits alphabétiquement. Unpublished doctoral dissertation, Université libre de Bruxelles.

Pring, L., \& SNowling, M. (1986). Developmental changes in word recognition: An information-processing account. Quarterly Journal of Experimental Psychology, 38A, 395-418.

Rossmeissl, P. G., \& Theios, J. (1982). Identification and pronunciation effects in verbal reaction time task for words, pseudowords, and letters. Memory \& Cognition, 10, 443-450.

Rosson, M. B. (1983). From SOFA to LOUCH: Lexical contributions to pseudoword pronunciation. Memory \& Cognition, 11, 152-160.

Rubenstein, H., Lewis, S. S., \& Rubenstein, M. A. (1971). Evidence for phonemic recoding in visual word recognition. Journal of Verbal Leaming \& Verbal Behavior, 10, 645-657.

SAFFran, E. M. (1985). Lexicalisation and reading preformance in surface dyslexia. In K. Patterson, J. C. Marshall, \& M. Coltheart (Eds.), Surface dyslexia: Neuropsychological and cognitive studies of phonological reading (pp. 53-71). Hillsdale, NJ: Erlbaum.

SeIDENRERG, M. S. (1985). The time course of phonological code activation in two writing systems. Cognition, 19, 1-30.

Seidenierg, M. S., MCClelland, J. L. (1989). A distributed, developmental model of word recognition and naming. Psychological Review, 96, 523-568.

Seidenberg, M. S., Waters, G. S., Barnes, M. A., \& Tanenhaus, M. K. (1984). When does irregular spelling or pronunciation influence word recognition? Journal of Verbal Learning \& Verbal Behavior, 23, 383-404.

Shallice, T., McCarthy, R. (1985). Phonological reading: From patterns of impairment to possible procedures. In K. E. Patterson, J. C. Marshall, \& M. Coltheart (Eds.), Surface dyslexia: Neuropsychological and cognitive studies of phonological reading (pp. 361397). Hillsdale, NJ: Erlbaum.

Stanhope, N., \& Parkin, A. J. (1987). Further explorations of the consistency effect in word and nonword pronunciation. Memory \& Cognition, 15, 169-179.

TABossi, P. (1989, April). La lectura en un lenguaje con ortografia superficial: Consideraciones teoricas y metodologicas. Paper presented at the fifth symposium of the Escuelas de Logopedia y Psicologia del lenguaje, Salamanca.

Taraban, R., \& MCClelland, J. L. (1987). Conspiracy effects in word pronunciation. Journal of Memory \& Language, 26, 608-631.

Theios, J., \& MuISE, J. G. (1977). The word identification process in reading. In N. J. Castellan, D. B. Pisoni, \& R. Potts (Eds.), Cognitive theory (Vol. 2, pp. 321-327). Hillsdale, NJ: Erlbaum.

VÉroNTS, J. (1986). Énde quantitative sur le système graphique et phonographique du français. Cahiers de Psychologie Cognitive, 6, 501-531.

\section{NOTES}

1. Note that this is not true for words. Contrary to Glushko's initial finding (1979), in Stanhope and Parkin's sudy (1987; see also Peereman, 1989; Seidenberg et al., 1984; Taraban \& McClelland, 1987) regular words with an irregular neighbor (the "inconsistent" words, in Glushko's terminology) were not pronounced more slowly than were regular words without irregular neighbors (the "consistent" words).

2. The central feature of the test pseudoword is that it be orthographically close to a word favoring either a correct or an incorrect pronunciation of the letter $g$. Because of difficulties in finding pseudowords whose neighborhood favored only one of the two pronunciations, it was not possible to balance the number of hard and soft $g$ pronunciations across conditions. 
APPENDIX A

Stimuli in Experiment 1

\begin{tabular}{|c|c|c|}
\hline Tests & (French Word, English Translation) & Controls \\
\hline \multicolumn{3}{|c|}{ Nonhomophonic Pseudowords } \\
\hline gidget & (gadget, gadget) & girvet \\
\hline gelf & (golf, golf) & gers \\
\hline gez & (gaz, gas) & ges \\
\hline gilerie & (galerie, gallery) & gimarie \\
\hline gilop & (galop, gallop) & gibor \\
\hline girnir & (garnir, to adorn) & girler \\
\hline gerrot & (garrot, tourniquet) & geclot \\
\hline gezelle & (gazelle, gazelle) & gevulle \\
\hline gizon & (gazon, grass) & girol \\
\hline goler & (geler, to freeze) & govir \\
\hline budgot & (budget, budget) & murgot \\
\hline fugice & (fugace, fugacious) & ragide \\
\hline wagin & (wagon, wagon) & regin \\
\hline engon & (engin, engine) & algon \\
\hline égird & (égard, consideration) & ogirs \\
\hline argole & (argile, clay) & ergone \\
\hline bigeme & (bigame, bigamist) & mageme \\
\hline mongil & (mongol, Mongol) & tongir \\
\hline agonce & (agence, agency) & egonre \\
\hline régont & (régent, regent) & bagont \\
\hline cigere & (cigare, cigar) & tagere \\
\hline logaque & (logique, logic) & vigaque \\
\hline gezette & (gazette, gazette) & gevutte \\
\hline \multicolumn{3}{|c|}{ Homophonic-If-Erroneous Pseudowords } \\
\hline gustice & (justice, justice) & gulmice \\
\hline gudo & (judo, judo) & guva \\
\hline gambon & (jambon, ham) & ganlin \\
\hline gardin & (jardin, garden) & gastin \\
\hline gumeau & (jumeau, twin) & gureau \\
\hline gaune & (jaune, yellow) & gausi \\
\hline galoux & (jaloux, jealous) & garoul \\
\hline gabot & (jabot, crop) & garit \\
\hline gavelot & (javelot, javelin) & gamevot \\
\hline gument & (jument, mare) & guvant \\
\hline gunior & (junior, junior) & gusiot \\
\hline gockey & (jockey, jockey) & goclet \\
\hline acagou & (acajou, mahogany) & ebagou \\
\hline pygama & (pyjama, pajamas) & mogama \\
\hline bagoue & (bajoue, cheek) & vagout \\
\hline ingure & (injure, insult) & ongule \\
\hline gougat & (goujat, boor) & goigas \\
\hline dongon & (donjon, dungeon) & ringor \\
\hline segour & (séjour, stay) & tagour \\
\hline bango & (banjo, banjo) & lengo \\
\hline migoter & (mijoter, to simmer) & tigover \\
\hline adgurer & (adjurer, to adjure) & arguler \\
\hline bongour & (bonjour, good day) & mangour \\
\hline cagoler & (cajoler, to cajole) & nagoser \\
\hline aguster & (ajuster, to adjust) & ogustir \\
\hline muget & (muguet, lily of the valley) & baget \\
\hline gichet & (guichet, wicket) & gipret \\
\hline droge & (drogue, drug) & vloge \\
\hline \multicolumn{3}{|c|}{ Homophonic-If-Correct Pseudowords } \\
\hline geudi & (jeudi, Thursday) & geuma \\
\hline geter & (jeter, to throw) & gevir \\
\hline geune & (jeune, young) & geube \\
\hline
\end{tabular}


APPENDIX A (Continued)

\begin{tabular}{lll}
\hline \multicolumn{1}{c}{ Tests } & (French Word, English Translation) & \multicolumn{1}{c}{ Controls } \\
\hline geux & (jeux, games) & geur \\
engeu & (enjeu, stake) & ongeu \\
reget & (rejet, rejection) & taget \\
suget & (sujet, subject) & baget \\
geep & (jeep, jeep) & geeb \\
abgect & (abject, abject) & irgect \\
traget & (trajet, journey) & blaget \\
obgecter & (objecter, to raise) & adgecter \\
proget & (projet, plan) & braget \\
mageur & (majeur, major) & vageut \\
égecter & (Ejecter, to eject) & agerter \\
regeter & (rejeter, to throw again) & bageter \\
ingecter & (injecter, to inject) & ongectir \\
magesté & (majesté, majesty) & tagesme \\
dégeuner & (déjeuner, lunch) & lageuner \\
obget & (objet, article) & ulget \\
adgectif & (adjectif, adjective) & apgertif \\
obgectif & (objectif, aim) & ubgertif \\
regeton & (rejeton, descendant) & bageton \\
\hline
\end{tabular}

APPENDIX B

Stimuli in Experiment 2

\begin{tabular}{ll}
\hline \multicolumn{1}{c}{ Homophonic-If-Erroneous } & \multicolumn{1}{c}{ Controls } \\
\hline gichet (guichet, wicket) & cuteau (couteau, knife) \\
ganre (genre, kind) & donse (danse, dance) \\
gitare (guitare, guitar) & pignet (poignet, wrist) \\
pigon (pigeon, pigeon) & vapur (vapeur, vapor) \\
droge (drogue, drug) & chime (chimie, chemistry) \\
gunior (junior, junior) & lusion (fusion, fusion) \\
gumeau (jumeau, twin) & voseau (roseau, reed) \\
gument (jument, mare) & niment (ciment, cement) \\
urgant (urgent, urgent) & absont (absent, absent) \\
muget (muguet, lily of the valley) & boxur (boxeur, boxer) \\
blage (blague, joke) & chane (chance, chance) \\
fatige (fatigue, fatigue) & journe (journée, day) \\
gépard (guépard, cheetah) & pussin (poussin, chick) \\
dongon (donjon, dungeon) & dinron (dindon, turkey) \\
gambon (jambon, ham) & sarton (carton, cardboard) \\
gougat (goujat, boor) & boutet (boulet, cannonball) \\
ségour (séjour, stay) & husour (humour, humor) \\
galoux (jaloux, jealous) & jalais (palais, palace) \\
gantil (gentil, pretty) & purdon (pardon, pardon) \\
agance (agence, agency) & oringe (orange, orange) \\
ingure (injure, insult) & orpane (organe, organ) \\
\hline
\end{tabular}

Note-The French word and its English translation are given in parentheses.

(Manuscript received January 11, 1990;

revision accepted for publication March 29, 1991.) 